\title{
Resource Scheduling Scheme for Multimedia Service Provisioning in Ubiquitous Environment
}

\author{
Dong Cheul Lee ${ }^{1}$, Bok Kyu Hwang ${ }^{1}$ and Byungjoo Park² \\ ${ }^{1} \mathrm{KT}$, \\ ${ }^{2}$ Hannam University \\ Republic of Korea
}

\section{Introduction}

In telecommunication industry, field resources had many tasks to visit customers and have provided network provisioning services. In the meantime, the amount of tasks and the diversity of customer's needs were overwhelming and the available human resources were not sufficient. To solve this problem, many telecoms had transformed field environment into ubiquitous environment. Thus, the resources carried a portable hand held device so that they could get detail information of the tasks and could transmit the results of the task at anywhere after they finished the task. Also, they could enable or disable the operation of network interfaces remotely. Furthermore, telecoms had adopted work team based appointment reservation system to manage the human resource's schedules. By using this system, call center operators could take customer calls, arrange appointments, and assign the tasks to work teams for service provisioning. And each resource could retrieve the task which was assigned to its team.

However, this system has several disadvantages. First, the operators can not know precise time when the resource can visit the customer site. Second, the resources retrieve tasks which were assigned to their team by themselves so that the tasks might not be distributed evenly. Third, if an urgent task, which should be done quickly, has assigned to a team, work managers should find suitable resources quickly because there is no time to wait until the resources retrieve the task by them selves. However, work managers do not have enough information to decide which resources would be the best to finish the task quickly.

There have been many studies about resource scheduling. Since a resource should visit a customer site, modeling this problem can be treated as a vehicle routing problem (Laporte et al., 2000). To find a near optimal solution for this, CVRPTW(Capacitated-Vehicle Routing Program with Time Window) (Schumitt et al., 2004) and the fast local search and guided local search (Tsang \& Voudouris, 1997) which simplifies a complicated real world problem to a similar simple well-known theoretical model were suggested. However, these static scheduling approaches were not efficient in dynamic environment. British Telecom had suggested several dynamic scheduling method, such as dynamic scheduling (Lesant et al., 2000) and dynamic scheduler for work manager (Lesant et al., 1998), but they were not suitable for the operators who should arrange visiting time and assign tasks in real time. We propose an individual resource scheduling system especially to address resource scheduling

Source: Convergence and Hybrid Information Technologies, Book edited by: Marius Crisan,

ISBN 978-953-307-068-1, pp. 426, March 2010, INTECH, Croatia, downloaded from SCIYO.COM 
challenge in ubiquitous and dynamic environment for provisioning multimedia services at telecom.

\section{Resource scheduling problem}

Previously, telecoms had used a work team based scheduling system which was assigning tasks to work teams as described in Fig. 1. When a customer requests a service, an operator in a call center searches suitable work teams. Those work teams should have been in charge of the work regions which includes the customer site because work regions are managed by work teams. Also, the total number of allocated tasks of the teams should not exceed maximum allocation count. To prevent concentrated allocations to a team, maximum allocation counts are managed by team hourly. After the operator selected a suitable team among the teams which satisfying a work region constraint and a maximum allocation count constraint, the task is assigned to the team so that any available resources in the team can dispatch the task and offers the service to the customer. While they are processing their tasks, work managers are monitoring the progress of the tasks, and re-schedule the delayed task if necessary.

However, as we mentioned before, this scheduling approach has several disadvantages since the scheduling process is based on the work team. Therefore, we propose individual resource based scheduling process which assigns tasks to the resource directly as described in Fig 1. In this process, when a customer requests a service, the operator searches suitable resources to deliver the service. Since work regions are managed by resources in this process, the selected resource should have been in charge of the work region which includes the customer site. Work regions are small enough not to make the resources travel for a long time. Also, the resources that have available time slot can be chosen by the system to assign the task and the time slot is managed per 15 minutes.

\section{System architecture}

To tackle individual resource scheduling challenge, we designed the system architecture as shown in Fig. 2. The Schedule Visualizer works as an interface between operators and the scheduling system and visualizes the schedules of resources. It gets schedule data from the Schedule Manager after the Schedule Manager computes an optimal solution for selecting the resources using the Human Resource Manager, the Task Duration Estimator, and the Driving Time Estimator. The resources input their day off, holiday duty, night shift, and business trip information to the Human Resource Manager. The Task Duration Estimator estimates the duration of a task before the reousrce actually does the task. Also, the Driving Time Estimator estimates the resource's moving time from one customer site to another before they actually move.

\subsection{Task Duration Estimator}

When a customer requests a service to a call center operator, the operator should be able to estimate the duration of the task to reserve the resource's schedule. Arrival time of the resource can be easily known since a customer wants specific visit time. However, the finish time of the task is hard to estimate since the duration of a task can vary with the resource's experience, service type, and provided network facilities. 


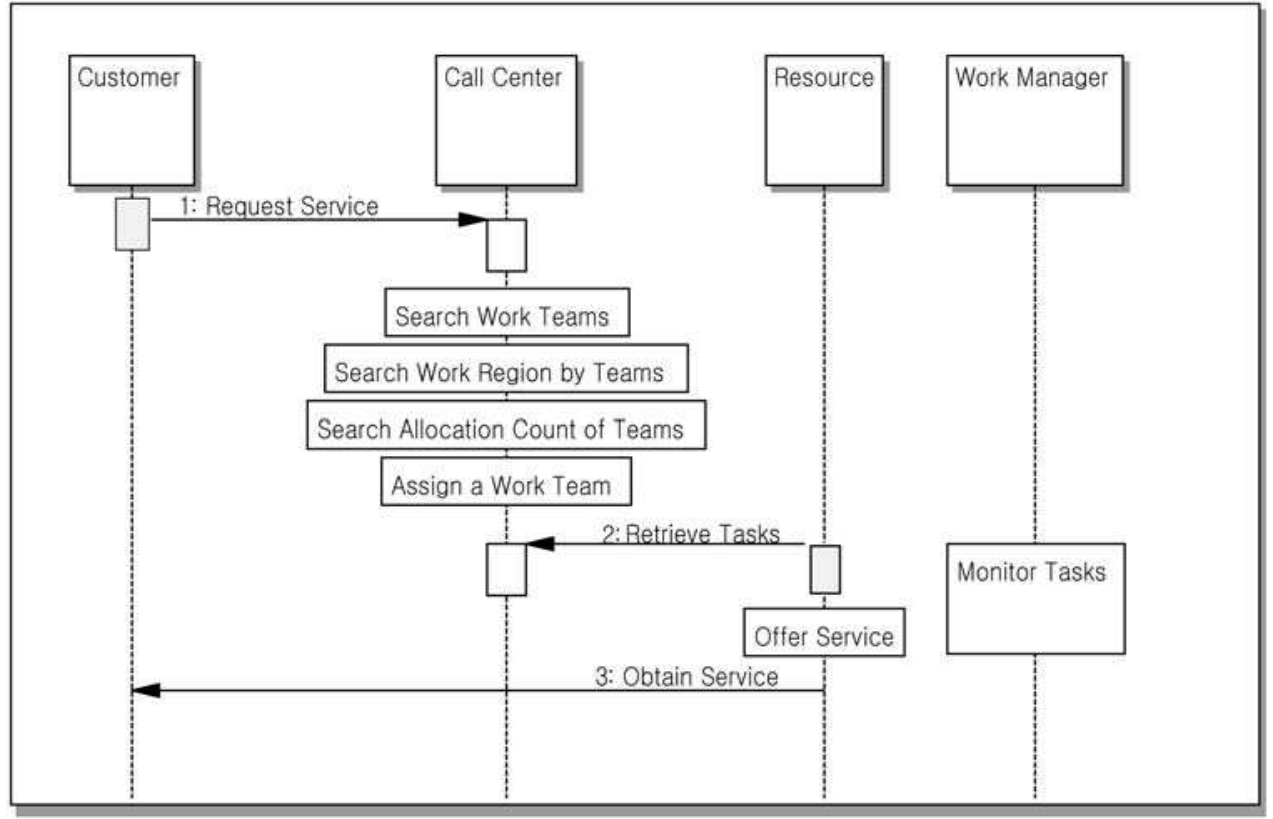

(a) The work flow of the work team based scheduling scheme

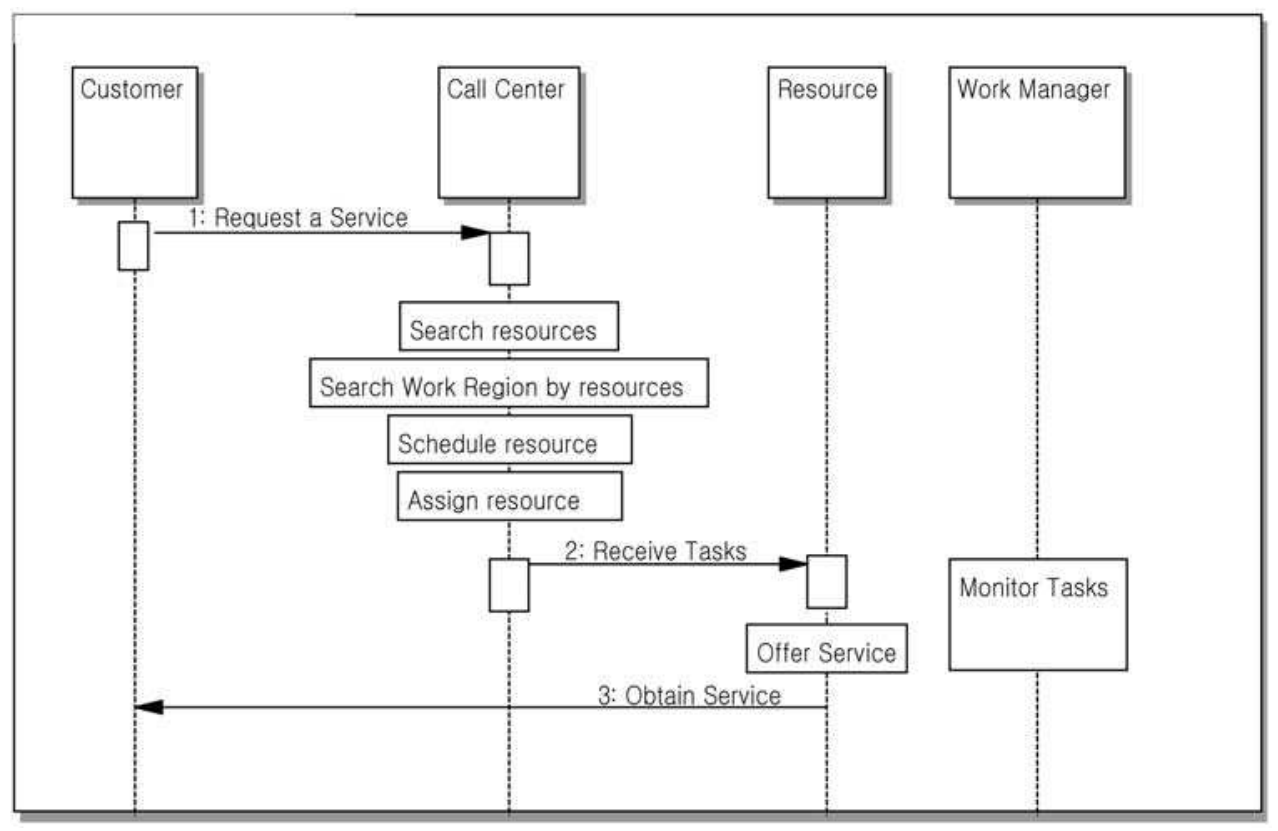

(b) The work flow of the individual resource based scheduling scheme

Fig. 1. The work flow comparisons between previous and suggested schemes 


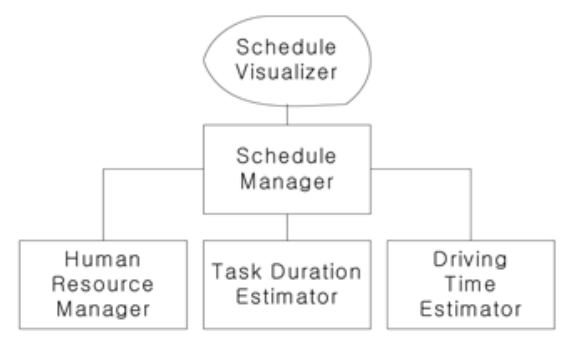

Fig. 2. System Architecture

The Task Duration Estimator can estimate the duration of a task by using statistical data. It calculates and stores the mean duration of previous tasks for each task type and resource. The task types can be classified by the service and the network facility. The multimedia services includes POTS, broadband, IP TV, and VoIP. And the network facilities are classified into FTTH, hybrid FTTH, xDSL, IP-xDSL, and Fast Ethernet. Furthermore, the duration can be varied by the day of the week and a time zone. The time zone is classified into forenoon, afternoon, and night. As a result, the mean duration $\mu(n)_{d u r}$ is managed by resource ID, the service type, the facility type, the day of the week, and the time zone. And it is calculated as follows:

$$
\mu(n)_{d u r}=\frac{\sum_{i=1}^{n} \tau(i)_{f t}-\tau(i)_{a t}}{n}
$$

$\tau(i)_{f t}$ means the time when the resource had completed the $i$ th task and it can be obtained when the resource had finished its task and sent the result to the system. $\tau(i)_{a t}$ means the time when the resource had arrived at a customer site for the $i$ th task and it can be obtained when the resource had arrived at a customer site and notify the system of its arrival time. Whereas $n$ is the total number of tasks with same resource ID, service type, facility type, day of the week, and time zone in latest one month.

\subsection{Driving Time Estimator}

Even though call center operators can estimate the duration of the task by using the Task Duration Estimator, they should also consider departure time of the resource from a previous customer site. Therefore, they should also estimate the time to travel from a previous customer site to a next customer site. However, the driving time is hard to estimate since it can vary with moving distance, moving velocity. Also, there can be many uncertainties such as weather and traffic conditions.

The Driving Time Estimator estimates the driving time of the resource from one customer site to another by using statistical data. It calculates and stores mean velocity for each resource. The velocity of a resource for $i$ th task $v_{i}$ can be calculated as follows:

$$
v_{i}=\frac{\delta_{i}}{\tau(i)_{a t}-\tau(i-1)_{f t}}
$$

$\delta_{i}$ means the previous resource's driving distance from $i-1$ th customer site to $i$ th site. To find $\delta_{i}$, we used a Geographic Information System (GIS) with traffic function enabled. Since we 
can get the addresses of customers, the Driving Time Estimator converts the addresses to coordinates and computes the driving distance between two points by using GIS. Like the Task Duration Estimator, the driving time can be varied by the day of the week and a time zone. As a result, the mean $\mu(n)_{v e l}$ velocity is managed by resource ID, the day of the week, and the time zone. And it is calculated as a harmonic mean (Bian \& Tao, 2008) like an equation (3).

$$
\mu(n)_{v e l}=\frac{1}{\frac{1}{n} \sum_{i=1}^{n} \frac{1}{v_{i}}}
$$

$n$ is the total number of tasks with same resource ID, day of the week, and a time zone in one month. If a resource started the first task on a day, $\tau(0)_{f t}$ means nine $\mathrm{O}^{\prime}$ clock since they had started their work at that time. Also, $\delta_{1}$ means the distance from their local office to a customer site. Therefore, when an operator wants to assign a task to a resource, the Driving Time Estimator calculates the distance from the current location of the resource to the location of the tasks by using a GIS. Also it can estimate the driving time by dividing the mean velocity $\mu(n)_{v e l}$ into the distance.

\subsection{Human Resource Manager}

The Human Resource Manager manages a day off, a holiday duty, a night shift, and business trip information of the resources. It is used for searching the available resources at a specific date by the Schedule Manager. If they had a day off or a business trip on a certain day, they are excluded from a resource pool at that time. On the other hand, if they put in a holiday duty or the night shift, they are included in the pool at that time.

\subsection{Schedule Manager}

Call center operators should search a suitable resource when they assign a task. If they choose a resource without any consideration at their convenience, they can not manage resource's schedule efficiently. However, finding a suitable resource by themselves is hard due to there are many factors to consider.

The Schedule Manager searches a near optimal resource for a task. It uses find_resource() algorithm to find a solution. The input value of the algorithm consists of $\tau(i)_{a t}$, service type, and work region. These values can be obtained while the operator talks over with a customer. It uses the Driving Time Estimator and the Task Duration Estimator to estimate the departure time and finish time for each resource. Also, the Human Resource Manager is used for excluding resources that don't work on weekday and including resources who work on holiday or at night.

\subsection{Schedule Visualizer}

Call center operators should be able to identify and monitor resource's schedule. The Schedule Visualizer displays resource's schedule and interacts with the operators. It represents the schedule as a Gantt Chart so that the operator can identify the status of the tasks. It also helps the work managers identify the task that is not likely to be completed on time so that they can rearrange the next task of the resource. 
Algorithm find_resource $\left(\tau(i)_{a t}\right.$, servicetype, workregion)

BEGIN

1. DEFINE wlist, templist as resource's list;

2. $\operatorname{IF}\left(\tau(i)_{a t}==h o l i d a y\right)$ THEN store resources who are responsible for a holiday duty into wlist;

$\operatorname{ELSE~IF~}\left(\tau(i)_{a t}==n i g h t\right)$ THEN store resources who are responsible for a night shift into $w$ wist;

ELSE store resources who don't have a day off or are not on a business trip into wlist;

3. exclude resources who are not in charge of the servicetype from wlist;

4. exclude resources who are not responsible for the workregion from wlist;

5. templist $=$ wlist;

6. DEFINE stime as the departure time for the task, ftime as the finish time of the task;

7. FOR(each resource $t$ in templist)

BEGIN

stime $=\tau(i)_{a t}$-DrivingTimeEstimator();

ftime $=\tau(i)_{u t}+$ TaskDurationEstimator();

IF time between stime and ftime is in other schedules of $t$ THEN exclude $t$ from templist;

END

8. IF templist is NULL THEN RETURN wlist;

9. IF templist has resources having no task THEN exclude resources who have tasks from templist;

10. delete resources from templist except top 5 resources with shortest (driving time+task duration);

11. IF (gap of (driving time+task duration) of resources in templist is within $10 \mathrm{~min}$ ) THEN delete resources from templist except resource with minimum tasks;

12. ELSE delete resources from templist except a resource with shortest (driving time+task duration);

13. RETURN templist;

Algorithm find_resource()

\section{Implementation}

The resource scheduling system consists of PC client, PDA client, application server, EAI server, and database server as shown in Fig. 3.

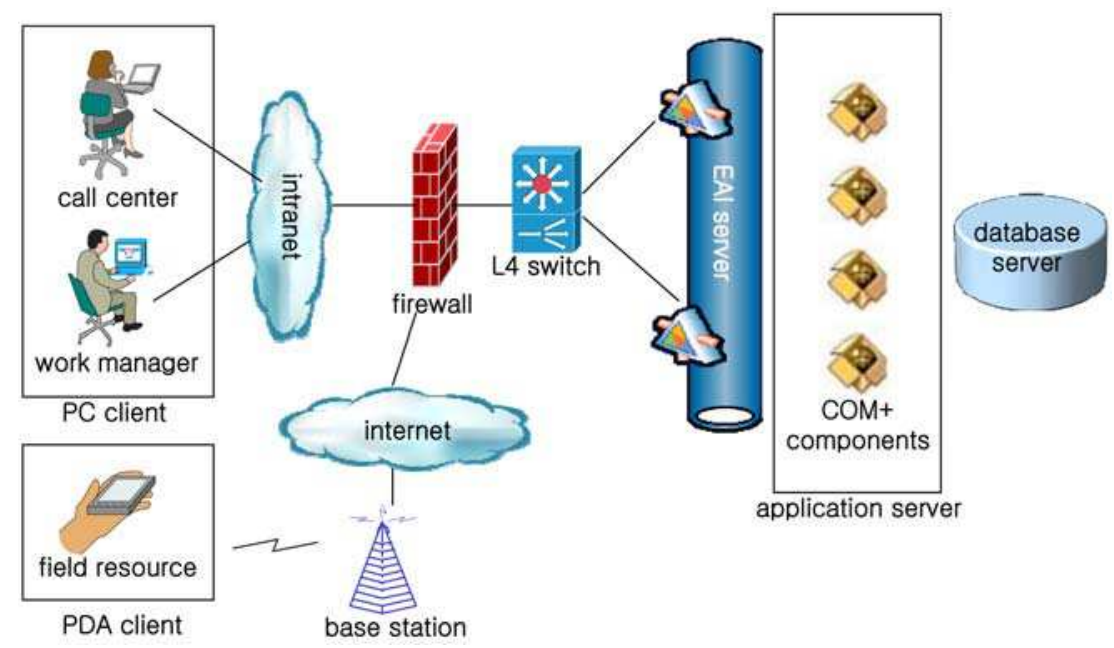

Fig. 3. Implementation 
The PC client is used by call center operators and work managers at local offices. They can get a suitable resource when assigning a task to a resource. They can also monitor the current status of the tasks whether there are delayed tasks. It is implemented as C/S method on .NET framework.

Field resources use the PDA clients when they process their tasks. They notify the application server of their arrival time and finish time by using the client. If an operator has assigned a task to a resource, the application server sends a short message to the client so that they can recheck their schedule and retrieve detail information from the server by using the client. The PDA client communicates with the application server on WiBro or CDMA2000 1x or EVDO network. It uses Windows Mobile .NET platform and MS SQL CE 2.0 DBMS. And it is implemented with C\# .NET.

The Driving Time Estimator and the Task Duration Estimator and the Schedule Manager and the Human Resource Manager are implemented in the application server as COM+ components. The server communicates with other systems or the clients via the EAI server. BizTalk Server 2004 is used for the EAI server. Both servers operate on Windows Server 2003 platform and load balanced by using L4 switch and protected by a firewall. Server applications are implemented with C\# .NET.

The database server stores tasks, schedules, and resources information from the application server and it uses MS SQL Server 2005 as a DBMS. Periodically executed stored procedures are registered as SQL Server jobs for calculating and storing the average durations of the tasks and the average driving velocities of the resources.

The system has been used at a telecom in Korea for scheduling field resources in specific area. To analize the efficiency of the system, we compared density distribution between previous and suggested scheme as shown in Fig. 4. The density distribution shows how many resources have done how many tasks in a day. The data were collected for one month, three times. The number of resources and tasks in the figure were modified for security reasons. Fig. 4 (a) shows the distribution of work team based scheduling scheme. We can identify that most resources can process $3 \sim 5$ tasks in a day. Fig. 4 (b) shows the distribution of individual resource based scheduling scheme. We can identify that most resources can process $5 \sim 7$ tasks in a day. Thus the resources can process about 2 more tasks in this environment. Therefore, we conclude that the resource can process more tasks by using our system.

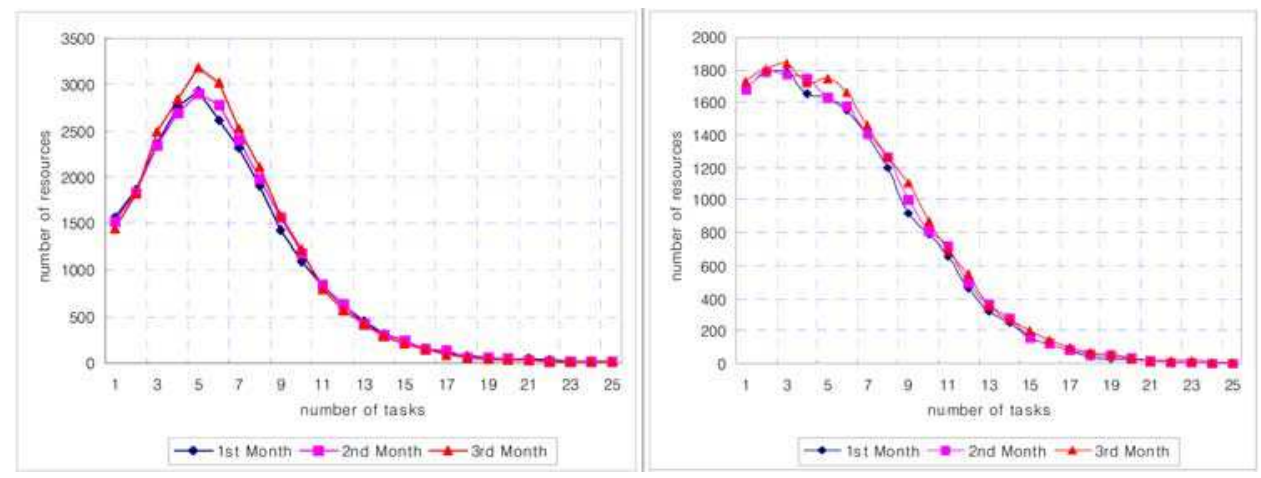

Fig. 4. The density distribution comparisons between work team based scheduling scheme and resource based scheduling scheme 


\section{Conclusion}

We proposed the resource scheduling system for multimedia service provisioning in ubiquitous environment. To solve this problem, we designed five modules which are the Task Duration Estimator, the Driving Time Estimator, the Schedule Visualizer, the Human Resource Manager, and Schedule Manager. They were implemented in a telecom, and the resources at the telecom could process more tasks after adopting the system. As a future work, we will improve the system to solve not only telecom's resource scheduling problem but also other resource scheduling problems.

\section{References}

Bian, W. \& Tao, D. (2008) Harmonic mean for subspace selection, 19th International Conference on Pattern Recognition, pp. 1-4, DOI:10.1109/ICPR.2008.4760987.

Laporte, G.; Gendreau, M.; Potvin, J.Y. \& Semet, F. (2000) Classical and modern heuristics for the Vehicle Routing Problem, International Transactions in Operational Research, Vol. 7, Issue 4-5, pp. 285-300, DOI:10.1111/j.1475-3995.2000.tb00200.x.

Lesaint, D.; Azarmi, N.; Laithwaite, R. \& Walker, P. (1998) Engineering Dynamic Scheduler for Work Manager, BT Technology Journal, Vol. 16, No. 3, pp. 16-29.

Lesant, D. ; Voudouris, C. \& Azarmi, N. (2000) Dynamic Workforce Scheduling for British Telecommunications plc, INTERFACES, Vol 30, No. 1, January-February, pp. 45-56.

Schumitt, L.J.; Aflaki, J.; Pitts, S.T. \& Kamery, R.H. (2004) An Emphasis on Heuristics Combined with GA to Improve the Quality of the Solutions: Some Methods Used to Solve VRPs and VRPTCs, Proceedings of the Academy of Information and Management Sciences, Vol. 8, Num. 1, pp. 53-58.

Tsang, E. \& Voudouris, C. (1997) Fast Local Search and Guided Local Search and Their Application to British Telecom's Workforce Scheduling Problem, Operations Research Letters, Vol. 20, Issue 3, pp. 119-127, DOI:10.1016/S0167-6377(96)00042-9. 


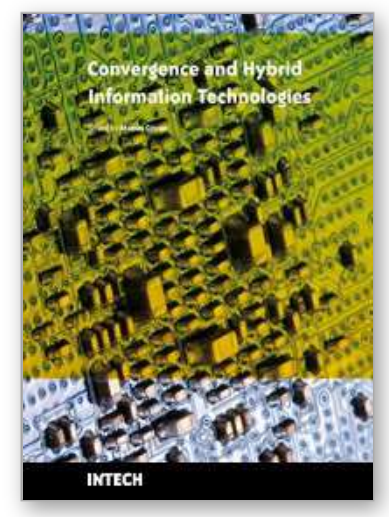

\author{
Convergence and Hybrid Information Technologies \\ Edited by Marius Crisan
}

ISBN 978-953-307-068-1

Hard cover, 426 pages

Publisher InTech

Published online 01, March, 2010

Published in print edition March, 2010

Starting a journey on the new path of converging information technologies is the aim of the present book. Extended on 27 chapters, the book provides the reader with some leading-edge research results regarding algorithms and information models, software frameworks, multimedia, information security, communication networks, and applications. Information technologies are only at the dawn of a massive transformation and adaptation to the complex demands of the new upcoming information society. It is not possible to achieve a thorough view of the field in one book. Nonetheless, the editor hopes that the book can at least offer the first step into the convergence domain of information technologies, and the reader will find it instructive and stimulating.

\title{
How to reference
}

In order to correctly reference this scholarly work, feel free to copy and paste the following:

Dong Cheul Lee, Bok Kyu Hwang and Byungjoo Park (2010). Resource Scheduling Scheme for Multimedia Service Provisioning in Ubiquitous Environment, Convergence and Hybrid Information Technologies, Marius Crisan (Ed.), ISBN: 978-953-307-068-1, InTech, Available from:

http://www.intechopen.com/books/convergence-and-hybrid-information-technologies/resource-schedulingscheme-for-multimedia-service-provisioning-in-ubiquitous-environment

\section{INTECH}

open science | open minds

\author{
InTech Europe \\ University Campus STeP Ri \\ Slavka Krautzeka 83/A \\ 51000 Rijeka, Croatia \\ Phone: +385 (51) 770447 \\ Fax: +385 (51) 686166 \\ www.intechopen.com
}

\author{
InTech China \\ Unit 405, Office Block, Hotel Equatorial Shanghai \\ No.65, Yan An Road (West), Shanghai, 200040, China \\ 中国上海市延安西路65号上海国际贵都大饭店办公楼405单元 \\ Phone: +86-21-62489820 \\ Fax: +86-21-62489821
}


(C) 2010 The Author(s). Licensee IntechOpen. This chapter is distributed under the terms of the Creative Commons Attribution-NonCommercialShareAlike-3.0 License, which permits use, distribution and reproduction for non-commercial purposes, provided the original is properly cited and derivative works building on this content are distributed under the same license. 